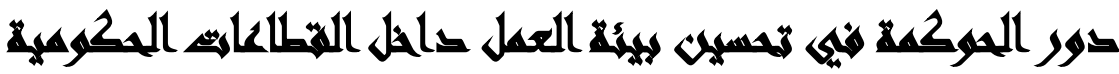

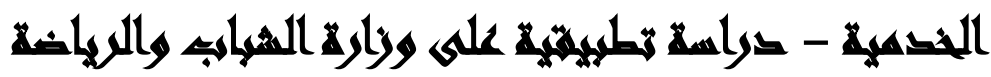

كراسما هيدانية

\author{
أحمد فوزي محمود أحمد(')- محمود عبد الهادي صبح(ץ) (ץ)
}

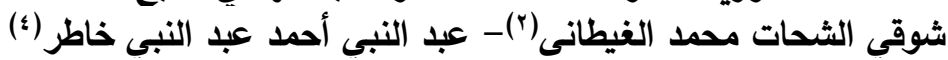

() طالب دراسات عليا بمعهد الدراسات والبحوث البيئية، جامعة عين شمس ك ج) كلية التجارة، جامعة عين شمس ץ) معهد الخذمة الاجتماعية بالقاهرة

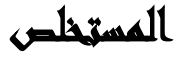

تهدف الدراسة إلى التعرف على دور الحوكمة في تحسين بيئة العمل داخل القطاعات

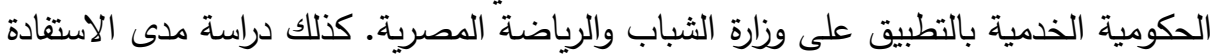

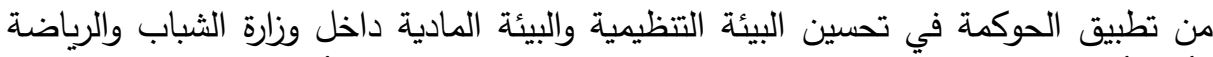

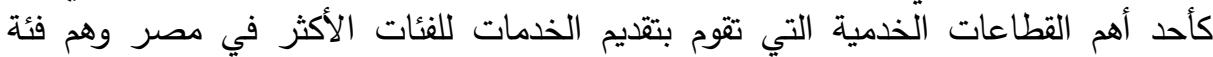

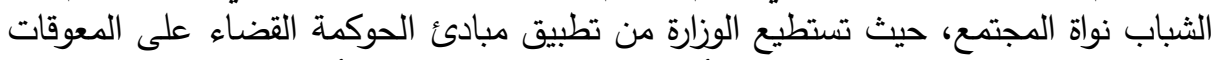

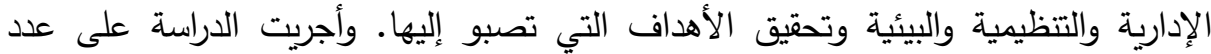

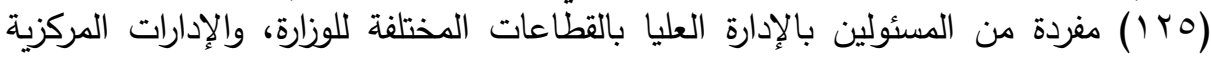

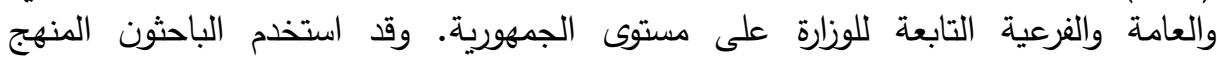

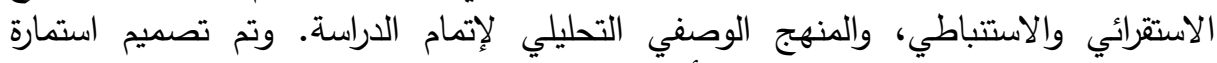
استبيان للمسئولين عينة الدراسة لقياس تأثير دور الحوكمة في تحسين البيئة التنظيمية والمادية والحد من الفساد.

وقد توصل الباحثون للنتائج التالية: توجد علاقة دالة إحصائيا بين الحوكمة وتحسين بيئة الحئة

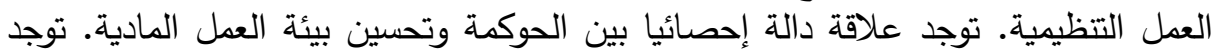
علاقة دالة إحصائيا بين الحوكمة وتحسين أداء العاملين. توجد علاقة داقة دالة إحصائة إلحائيا بين

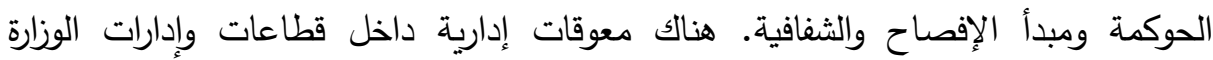
المختلفة تعوق من تطبيق نظام الحوكمة بثكل كامل.

$$
\begin{aligned}
& \text { r.Y. • المجلد التاسع والأربعون، العدد التاسع، الجزء السابع، سبتمبر } \\
& \text { الترقيم الدولي 0826- ISSN 1110 }
\end{aligned}
$$


كما خلصت الدراسة لبعض التوصيات أهمها: ضرورة تبنى تطبيق الحوكمة لتحسين

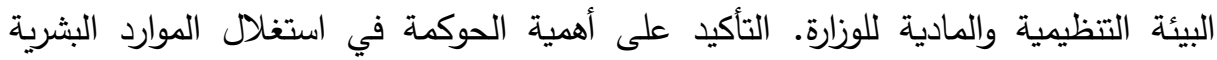
والمادية والحد من الفساد الإداري. الكلمات المفتاحية: الحوكمة، القطاعات الحكومية الخدمية، بيئة العمل.

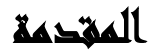

منذ منتصف التسعينات كانت المنظمات الدولية وعلى رأسها هيئة الأمم المتحدة ترتكز

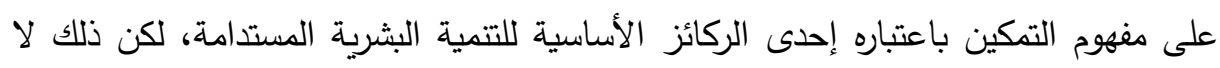

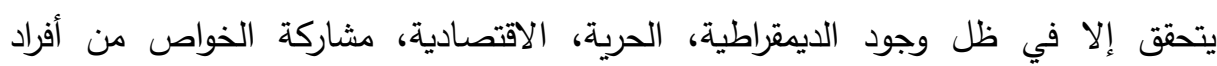
وجمعيات ومنظمات غير حكومية في صنع القرارات وتتفيذ الخطط، وقياسا على ذلك ظهرت مصطلحات أثثاء وضع هذه الإستراتيجية وهى المشاركة، الديمقراطية، الثفافية، المسائلة

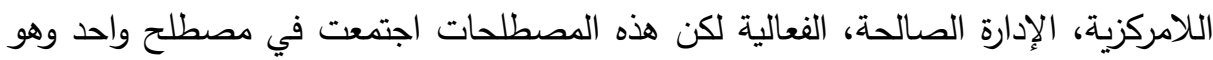

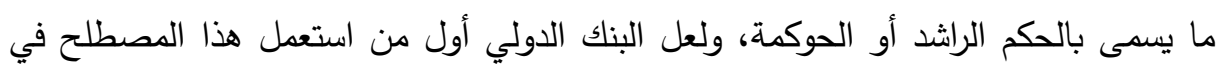

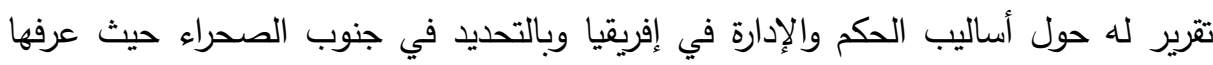

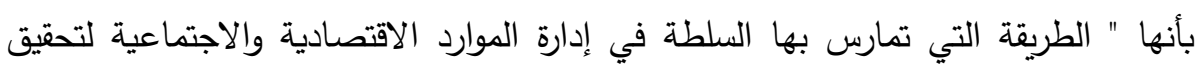

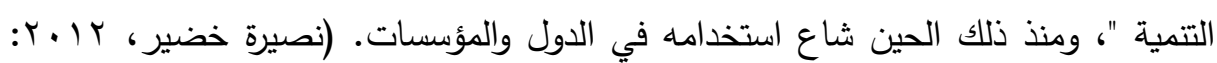

وحسب مفهوم حوكمة القطاع الحكومي الخدمي، فالثعب هنا يمثل العنصر الأساسي

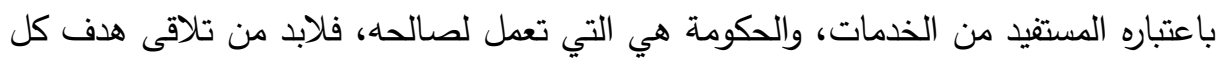

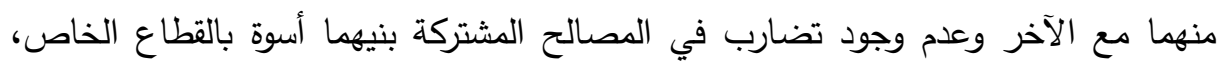
لكن الأضرار المترتبة على تضارب المصالح في القطاع العام ربما تكون أعم وأشمل وينتج تصنيج عنها آثاراً أكثر خطورة منها في القطاع الخاص بستبة تلبار تعنت المسئولين، والبيروقراطية الحكومية، واستغلال النفوذ والسلطات على حساب مصلحة العمل، فإن آثار انحراف

$$
\begin{aligned}
& \text { r.r. . المجلد التاسع والأربعون، العدد التاسع، الجزء السابع، سبتمبر }
\end{aligned}
$$

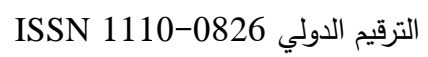


المسئولين بالقطاعات الحكومية تطال المجتمع ككل وربما تعطل تقدم المجتمع وتتميته، والتشجيع على انتشار استغلال النفوذ والإثراء غير المشروع حتى يصبح هذا الانحراف عملا مقبولا وجزءا من ثقافة المجتمع. إن الاهتمام بتطبيق نظام الحوكمة الرشيدة داخل المنظمات الحكومية الخدمية أهم وأكثر

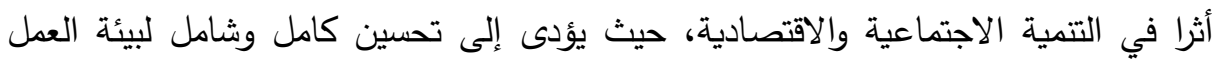

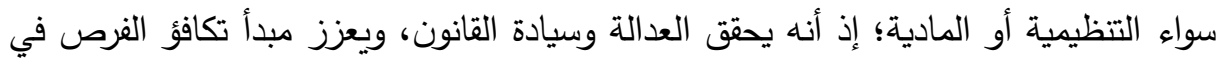
المجتمع ويحافظ على النظام المالي والاقتصادي للدولة، كما يساهم في تحسين البيئة الداخلية

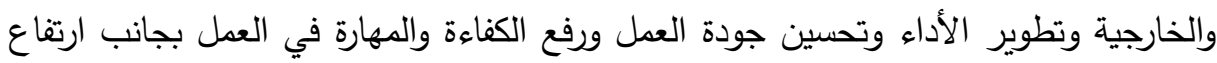
الروح المعنوية للعاملين وتحسين العلاقة ببينهم وبين الإدارة ورضاهم على العمل وتوجيه النشاط الذي يؤسس بيئة خدمية صالحة لإنتاجية جيدة ومتطورة.

\section{And ILan}

يُعد تبني مفهوم الحوكمة داخل القطاعات الحكومية ذات الطابع الخدمي أمرا صعب التطبيق والتتفيذ نظرا للبيروقراطية والروتين الإداري وغياب الثفافية والمساواة داخل البيئة

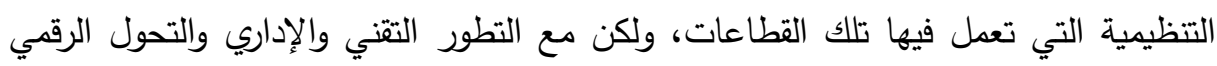

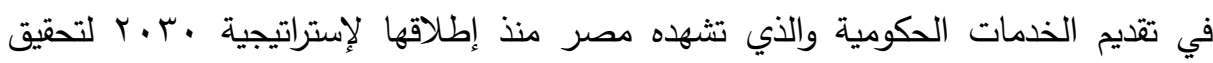

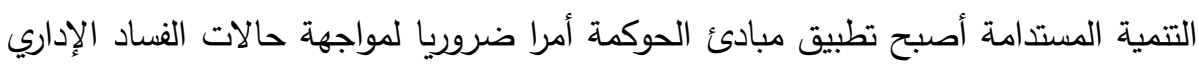
في القطاعات الخدمية المنتشرة داخل الوزارات الحكومية بمصر ولتحسين الأداء داخل بيئة

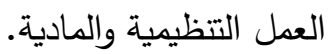
ومن هذا المنطلق تكمن مشكلة الدراسة في أنه بالرغم من كبر حجم العمل الإداري والخدمي داخل القطاعات المختلفة التابعة لوزارة الثباب والرياضة والتي تبلغ لتهن (• (1) إدارات

$$
\begin{aligned}
& \text { r. r. • المجلد التاسع والأبعون، العدد التاسع، الجزء السابع، سبتمبر } \\
& \text { الترقيم الدولي 0826-0 الإنون، }
\end{aligned}
$$


مركزية يتفرع منها عدد (^^) إدارة عامة تخدم قطاعين هما الثباب، والرياضة على مستوى

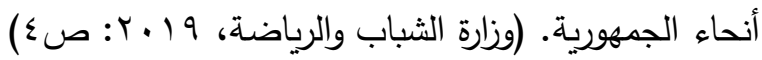

إلا أن هذه القطاعات لا تهتم باستخدام أداة إدارية إستراتيجية تتظيمية تقوم بمراقبة

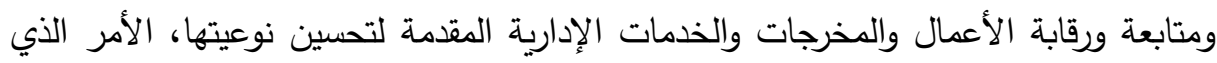

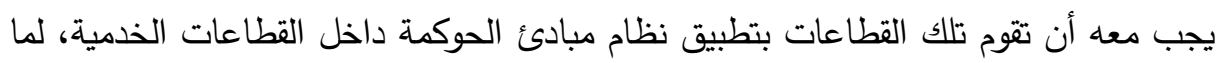

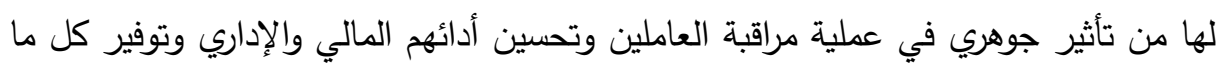
يؤدى إلى رفع كفاءة الخدمات المقدمة بكفاءة ودقة عالية، فضلا عن عن تحسين التهين البيئة التنظيمية الداخلية للقطاعات، وجعلها بيئة عمل مناسبة على مستوى كافة الاتجاهات الإدارية مما يزيد

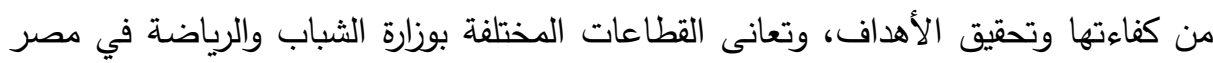

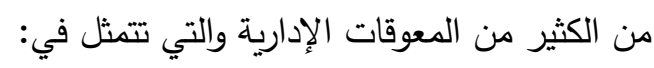

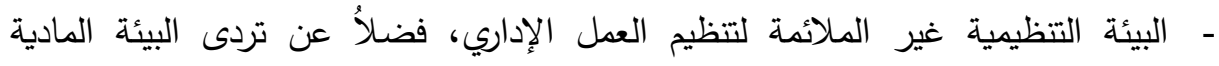
بالإدارات الإقليمية التابعة للوزارة. - تضارب الاختصاصات الإدارية لمراكز الثباب التابعة للمحافظات والقرى. - الروتين الإداري والذي يؤدى إلى الفساد وعدم المساءلة وسوء تقديم الخدمات.

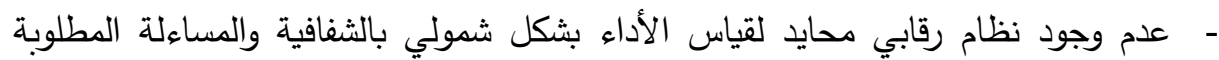
والاعتماد على الثئون القانونية الداخلية فقط. ومن هنا تبلورت مشكلة الدراسة لدى فكر "الباحثون" واستثعروا بخطورة المشكلة التي يجب إيجاد حلول لها، ورأى أنه من المفيد دراسة دور وأهمية تطبيق الحوكمة في تحسين البيئة التظظيمية داخل وزارة الثباب والرياضة كأحد أهم القطاعات الخدمية التي تقوم بتقديم

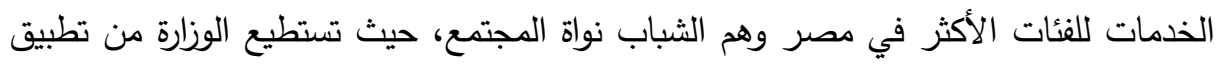

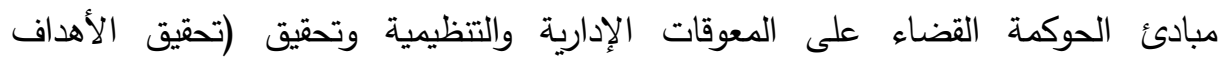
الإستراتيجية للوزارة- تقليل مخاطر الفساد المالي والإداري- القضاء على البيروقراطية والروتين 386

$$
\begin{aligned}
& \text { r.r. · المجلد التاسع والأربعون، العدد التاسع، الجزء السابع، سبتمبر } \\
& \text { الترقيم الدولي 0826-0 1110 }
\end{aligned}
$$




$$
\begin{aligned}
& \text { مجلة العلوم البيئية } \\
& \text { معهد الدراسات والبحوث البيئية - جامعة عين شمس له } \\
& \text { أحمد فوزي محمود وآخرون }
\end{aligned}
$$

الإداري- رفع مستويات الأداء الإداري-التحسين والتتظيم والتطوير المستدام للبيئة التنظيمية

$$
\text { والمادية- التحسين-تعزيز مكانة الوزارة ضمن الجهاز الحكومي). }
$$

\section{أسئلا الهمهي}

يحاول البحث الإجابة على السؤال الرئيس التالي: "ا دور الحوكمة في تحسين بيئة العمل

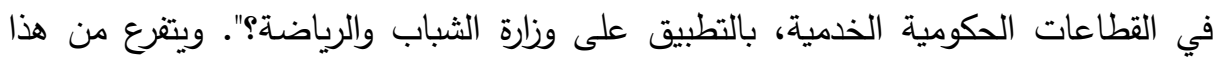
السؤال مجموعة من الأسئلة الفرعية التالية:

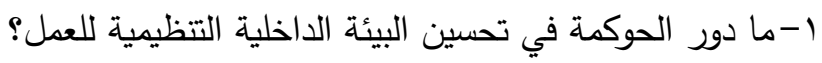
r-ما دور الحوكمة في تحسين البيئة المادية للعمل ؟ r- إلى أي مدى تلعب الحوكمة دورا فعالاً في تطوير وتحسين الأداء الإداري للعاملين؟ ع-إلى أي مدى تساهم الحوكمة في القضاء على الفساد الإداري داخل البيئة التنظيمية للعمل؟

0- إلى أي مدى توجد معوقات تواجه تطبيق مبادئ الحوكمة داخل وزارة الثباب والرياضة ؟

\section{أمسانهم الهمبش}

$$
\text { تهدف هذه الدراسة إلى ما يلي: }
$$

1- التعرف على دور الحوكمة في تحسين البيئة الداخلية التظظيمية للعمل. r- التعرف على دور الحوكمة في تحسين البيئة الداخلية المادية للعمل. r-توضيح الدور الفعال للحوكمة في تطوير وتحسين الأداء المالي والإداري للعاملين. ع-الوقوف على أهمية تطبيق الحوكمة في القضاء على الفساد المالي والإداري داخل البيئة التتظيمية للعمل.

ه- إبراز المعوقات التي تواجه تطبيق مبادئ الحوكمة داخل وزارة الثباب والرياضة.

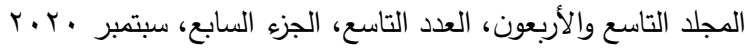

$$
\begin{aligned}
& \text { الترقيم الدولي 0826- ISSN 1110 }
\end{aligned}
$$




\section{هزوض المهيث}

في ضوء مشكلة وأهداف الدراسة يمكن صياغة فروض الدراسة علي النحو التالي: الفرض الرئيس الأول: توجد علاقة جوهرية بين الحوكمة وتحسين البيئة الداخلية للعمل (البيئة الإدارية - البيئة القانونية - البيئة المالية- تحسين وتطور الأداء - تحسين البيئة المادية). الفرض الرئيس الثاني: توجد علاقة جوهرية بين الحوكمة وتحسين الأداء (تحديث أنظمة وإجراءات العمل- التدريب المستمر - رفع وتطوير كفاءة العنصر البشرى- الثفافية) الفرض الرئيس الثالث: توجد علاقة جوهرية بين الحوكمة ومبدأ المساءلة والمحاسبة ومكافحة الفساد (المساءلة القانونية - المساءلة الإدارية - المساءلة المالية ).

\section{أهميد المهمث}

تكمن أهمية الدراسة في جانبين هما الجانب العلمي والجانب العملي كما يلي: الأهمية العلمية: تبدو الأهمية العلمية لموضوع الدراسة في أنها تتناول مفهوم إداري معاصر هو الحوكمة وأهمية تطبيق مبادئها في أحد أهم القطاعات الحكومية الخدمية، وهى وزارة لهنية الثباب والرياضة المصرية، حيث ترتكز مبادئ الحوكمة على إرساء مبادئ العدالة والثفافية والمساءلة، وتطوير أساليب العمل، والاهتمام بالموارد البشرية وضرورة تطوير وتتمية قدراتهم ومهاراتهم من خلال التعلم والتتريب والتحفيز واكتسابهم الخبرات وإطلاق مواهبهم وتعزيز العمل الجماعي وتحقيق الدافعية نحو الانجاز لرفع مستوى الأداء.

الأهمية التطبيقية: توضيح فاعلية وأهمية ودور الحوكمة في تحسين بيئة العمل التنظيمية لرئية والمادية داخل قطاعات الوزارة، بهدف تحسين بيئة العمل من الناحية الإدارية للعاملين، ورفع وتطوير وزيادة فعالية الأداء المؤسسي بشكل عام. 
تعتبر نتائج الدراسة وتوصياتها مساهمة فكرية وبحثية تضاف للباحثين في المجال الإداري بواسطة تطبيق مبادئ الحوكمة الرشيدة على القطاعات الخدمية داخل الجهاز الإداري والحكومي للدولة، بهدف ضبط وتحسين الخدمات المقدمة والأداء.

\section{السواسايس السابرية}

\section{دراسات وبحوث متعلقة بمفهوم الحوكمة:}

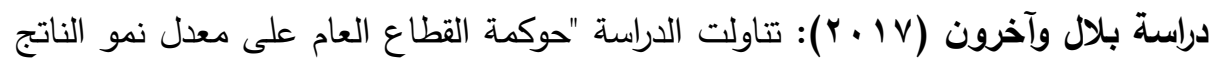
المحلي الإجمالي دراسة حالة المملكة الأردنية الهاشمية". وهدفت الدراسة إلى دراسة مفهوم وأهمية الحوكمة في القطاع العام، وإبراز أثر حوكمة القطاع العام على معدل نمو الناتج المحلي الإجمالي، وأثبتت نتائج الدراسة أن هناك غياب لتطبيق مفهوم الحوكمة بشكل كامل مما يؤدى لانتشار الفساد المالي والإداري، كما أن تبنى نظام الحوكمة يُعد الحل الأمثل لمواجهة الفساد الإداري بكافة أثكاله. دراسة (وليد هارون: 9 ( ـ ب): تتاولت الدراسة " تطبيق مبادئ الحوكمة ودورها في الحد من ظاهرة الفساد الرياضي داخل المؤسسة الرياضية-دراسة ميدانية بمديرية الثباب والرياضة لولاية برج بوعريريج". وهدفت الدراسة إلى التعرف على دور الحوكمة في الحد من ظاهرة الفساد الرياضي، وكذلك إبراز أهم الصعوبات التي تواجه تطبيق الحوكمة وأثبتت نتائج الدراسة أن هناك علاقة جوهرية بين الحوكمة والحد من الفساد الرياضي، كما أن هناك أهمية لتطبيق مبادئ الحوكمة فى المؤسسات الرياضية لما تملكه من آليات تستطيع من خلالها ضبط الأداء المالي والإداري لتلك المؤسسات. دراسة (Tanweer, et al:2019): تناولت الدراسة دور الحوكمة في أداء مؤسسات التمويل الصغيرة فى بنجلاديش. وهدفت الدراسة إلى التعرف على دور الحوكمة في تحسين أداء المؤسسات الصغيرة، كذلك التعرف على التعرف على مدى التأثير المحتمل لسمات الحوكمة

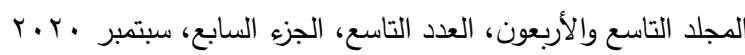

$$
\begin{aligned}
& \text { الترقيم الدولي 0826- ISSN 1110 }
\end{aligned}
$$


على الأداء المالي، وأثتتت نتائج الدراسة أنه توجد علاقة ارتباط بين الحوكمة وتحسين الأداء المالي. دراسات وبحوث متعلقة بييئة العمل: دراسة (2018: Glenda): تناولت الدراسة العلاقة بين بيئة العمل والانسجام وفعالية الأداء في بيئة القطاع العام. وهدفت الدراسة إلى فحص العلاقة بين الفعالية الإدارية وبيئة العمل، لإل، كذلك التعرف على مدى تأثير بيئة العمل على المستويات الإدارية الثلاثة ( العلياالدتوسطة- الدنيا). وأثتبت نتائج الدراسة أن هناك تأثير لبيئة العمل على الفعالية الإدارية

$$
\text { لجميع المستويات الإدارية الثلاثة ( العليا- المتوسطة - الدنيا). }
$$

دراسة (2019: :Sugeng, et al): تتاولت الدراسة تأثير بيئة العمل وأسلوب القيادة والالتزام التتظيمي على أداء العاملين. وهدفت الدراسة إلى التعرف على العلاقة بين البيئية المادية والالتزام التتظيمى، كذلك التعرف على مدى العلاقة بيئة وتأثيرها على أداء العاملين. وأثبتت نتائج الدراسة هناك تأثير ايجابي محدود على الالتزام التتظيمي الوظيفي والمتغيرات البيئية التتظيمية، كما أن هناك علاقة إيجابية بين البيئة المادية وتحسين أداء العاملين. دراسة ( 2020: Masood \& Qamar): تتاولت الدراسة آثار بيئة العمل على أداء الأطباء في مستثفيات القطاع العام في باكستان. وهدفت الدراسة إلى التعرف على الآثار

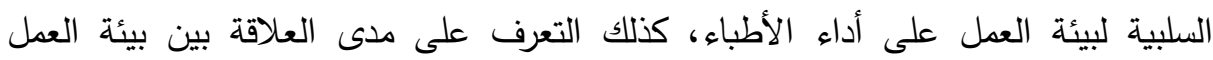
ومستوى الأداء الطبي. وأثبتت نتائج الدراسة العمل على تحسين الظروف البيئية الداخلية داخل المستشفيات، كذلك ضرورة إنثاء إدارة بيئية لكل مستثفى تهتم بكافة الظروف المحيطة بالمستثفيات. 


$$
\begin{aligned}
& \text { مجلة العلوم البيئية } \\
& \text { معهد الدراسات والبحوث البيئية - جامعة عين شمس لكس }
\end{aligned}
$$

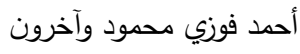

\section{الإطار اللنظيه}

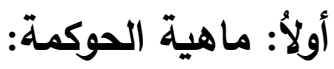

نشأة الحوكمة وتعريفها: لقد ظهرت فكرة الحوكمة من أكثر من مدرسة فكرية، فلقد جاءت هذه الفكرة في علم الإدارة وعلم السياسة، فمن الإدارة جاءت من مدرسة إدارة الجودة الثاملة، والتي

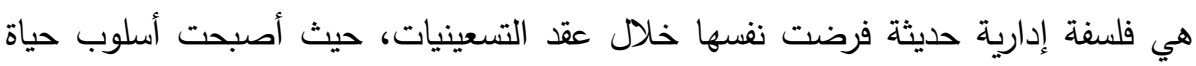

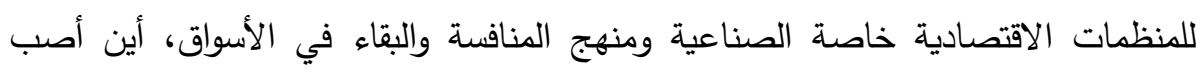

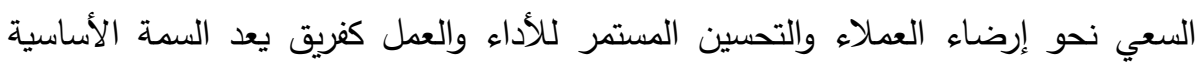

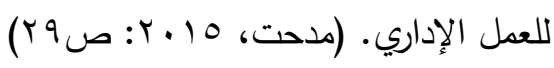
مفهوم الحوكمة على مستوى المنظمات: هي النظام الذي تستخدمه المنشأة في عملية

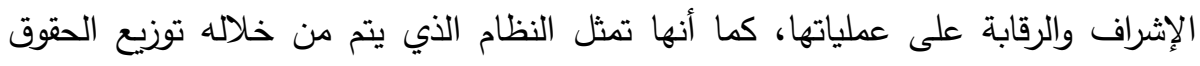

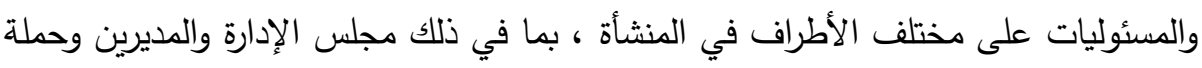

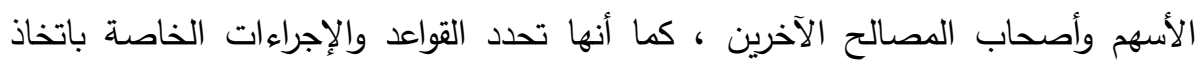

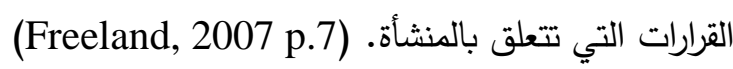
ثانياً: خصائص الحوكمة: يتضمن مصطلح حوكمة المؤسسات الخصائص التالية: • الانضباط: أي إتباع السلوك الأخلاقي المناسب والصحيح.

• الثفافية: بمعنى توافر كل من التعامل النزيه والدكتمل وما هو مطلوب من التقارير المالية

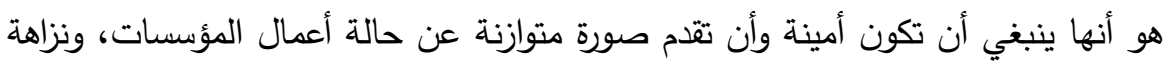

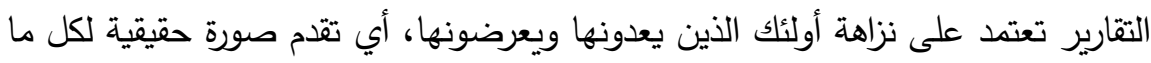


• المساءلة: مجالس الإدارة تكون مسئولة أمام مسئوليها ويقع على كليهما عبء القيام بدوره وجعل المسئولية فعالة ، فمجالس الإدارة في حاجة إلى تحقيق هذا من خلال جودة

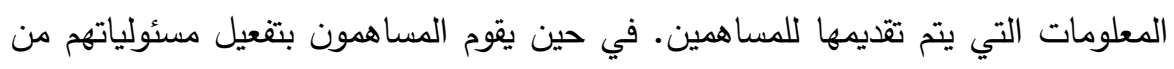
خلال ممارسة مسئولياتهم كملاك، أي إمكان تقييم وتقدير أعمال مجلس الإدارة والإدارة

التتفيذية.

• المسؤلية: أي وجود مسؤولية أما جميع الأطراف ذوي المصلحة في الثركة.

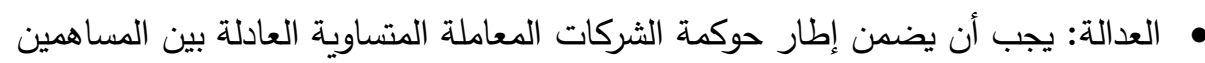
أي يجب احترام حقوق المجموعات أصحاب المصلحة في الثركة. • المسؤولية الاجتماعية: أي النظر إلى الثركة كمواطن جيد ويجب على الثى المؤسسة زيادة

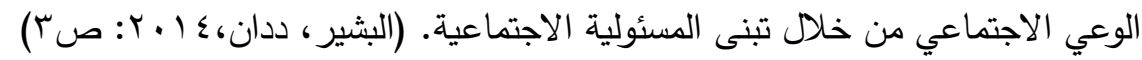
ثالثاً: مفهوم القطاعات الحكومية الخدمية: هي تلك المرافق التي تؤدي خدمات مباشرة للجمهور المستفيد مثل الخدمات البلدية والصحية والبريدية والتعليمية، وخدمات الجوازات

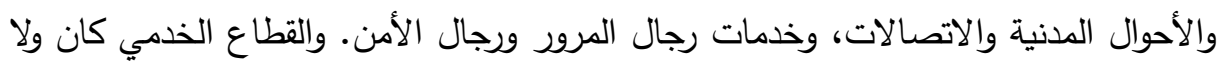
يزال وسوف يظل مدار الحديث ومثار الجدل والتحليل والدراسات من قبل الأكاديميين والكتاب ولهاب والباحثين والنقاد، ومن قبل المخططين وراسمي السياسات والقيادات الإدارية في أجهزة الدولة وخارجها. بسبب ملامسة القطاع الخدمي لاحتياجات الناس وتطلعاتهم للحصول على خدمات ترقى إلى مستوى التميز وإثعار المستفيدين منها بعزتهم وكرامتهم وأنهم أهل للخدمات المتميزة.

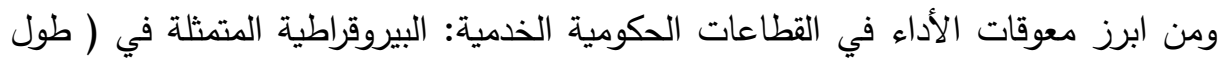
الإجراءات وتعقيدها، تفشي المحسوبية في تقديم بعض الخدمات ضعف إدف استخدام التقنية

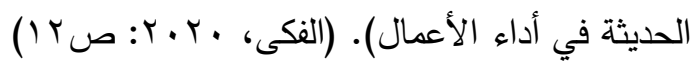

رابعاً: الحوكمة في القطاعات الحكومية الخدمية: تُعد الحوكمة في القطاع الحكومي أو الخدمي أحد الأساليب التنظيمية الإدارية التي تساعد الحكومات على تحقيق أهدافها 392

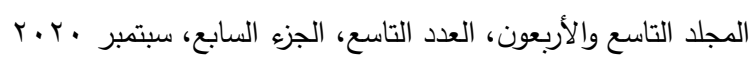

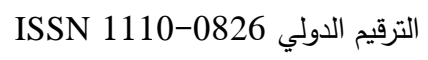


التتموية عن طريق إشراك المستفيدين من الخدمات العامة في إدارة شئون الدولة وعلى الرغم

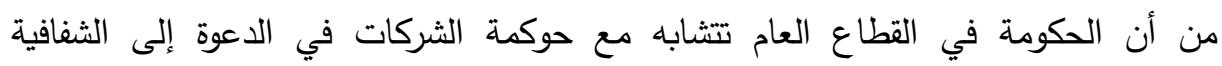
والإفصاح، فان الحوكمة في القطاع العام تثمل أيضا تطبيق مبادئ سيادة القانون والمحاسبة والمساءلة وذلك بدعم وتعزيز مشاركة المواطنين ومنظمات المجتمع المدني ومؤسسات الأعمال في صياغة وإعداد السياسات العامة واتخاذ القرارات وتتفيذها.

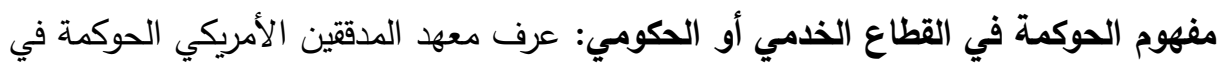

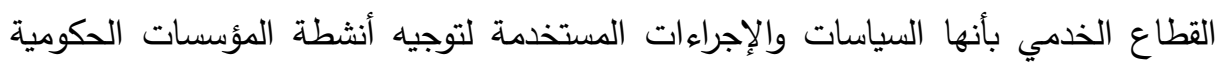

$$
\text { - }
$$

- التعبير عن مدى انجاز وتحقيق الأهداف المرجوة من خلال القيام بالأنثطة التي تضمن مصداقية الحكومة.

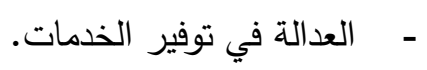

- وضمان السلوك المناسب والأخلاق للمسئولين الحكوميين للحد من مخاطر الفساد المالي

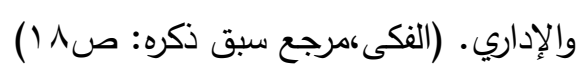

أهمية الحوكمة في القطاعات الخدمية: تعود أهمية الحوكمة في القطاعات الخدمية من حيث الإري

1-توفر هيكلاً تنظيمياً يُكنها من تحقيق أهدافها بأفضل السبل المكنة.

$$
\text { r-تحقق الاستثمار الأمثل للموارد. }
$$

ب-تُشأ نظام رقابة وإشراف ذاتي يؤدى لسلامة التطبيق القانوني للتشريعات.

ع-تعمل على تجنب الفساد المالي والإداري.

ه-تقوم بالكثف عن أوجه القصور في الأداء وضعف المخرجات الدات.

$$
\begin{aligned}
& \text { r.r. . المجلد التاسع والأربعون، العدد التاسع، الجزء السابع، سبتمبر }
\end{aligned}
$$

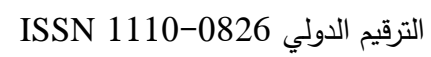


7-تهتم بحقوق ومصالح المؤسسة والعاملين بها.

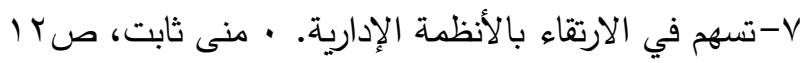

أهداف حوكمة القطاع الحكومي والخذمي: ترجع غاية الحوكمة في القطاع الحكومي والخدمي تاني في تعزيز ثقة المواطنين بالدولة ومؤسساتها من خلال تحقيق الأهداف الآتية:

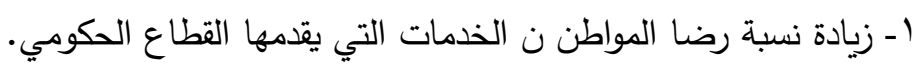

r- تحقيق مبدأ المحاسبة والمساءلة للدوائر الحكومية وما فيها، والالتزام بالقوانين والأمانة.

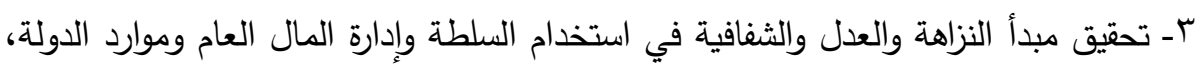

والحد من استغلال السلطة العامة لأغراض خاصة. ـ - تحقيق تكافؤ الفرص بين المواطنين.

0ـ تحقيق الحماية اللازمة للملكية العامة مع مراعاة مصالح الأطراف ذات العلاقة.

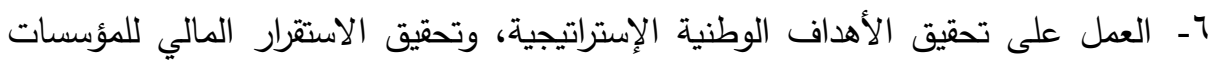
الحكومية.

V- رفع مستوى قدرات الدوائر الحكومية من خلل تعزيز وتطوير الأداء المؤسسي عن طريق

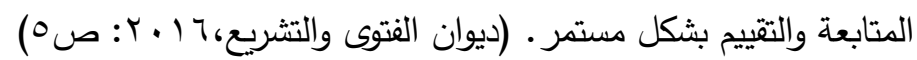
الآثار السلبية لعدم تطبيق الحوكمة في القطاعات الخدمية: هناك آثاراً سلبية تعانى منها

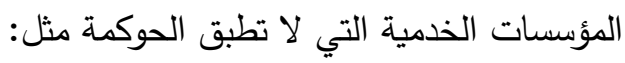

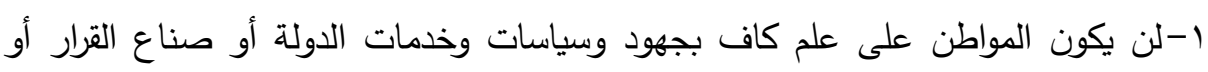
مقدمي الخدمات، وبالتالي لن يكون هناك أي استيعاب من جانب المجتمع لتلك الجهود. r-لن تخرج الرؤى والسياسات والخدمات بصورة تثاركية تعكس احتياجات المجتمع وتوقعاته. ب-لن يتم محاسبة غير الملتزمين من المسئولين وغيرهم.

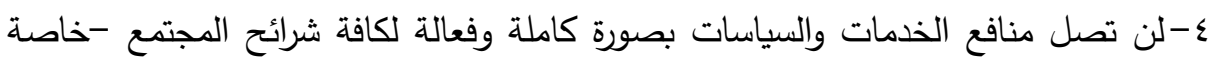
الفقراء وغير القادرين - وستتتج فروقا في جودة وإتاحة الخدمة بين الطبقات الاجتماعية.

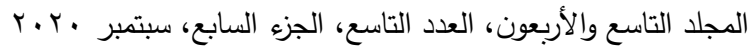

$$
\begin{aligned}
& \text { الترقيم الدولي 0826-0 1110 }
\end{aligned}
$$


0- إهدار الموارد لتدنى الكفاءة وانتشار الفساد، حيث يؤدى كلاهما إلى تسرب موارد كان من

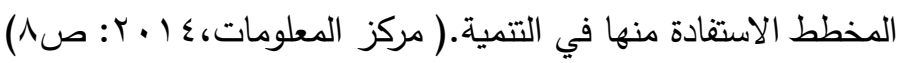
فوائد ومزايا تطبيق الحوكمة في القطاعات الخدمية: للحوكمة فوائد ومزايا عديدة في القطاعات الخدمية للدولة يمكن سردها كالآتي: 1-زيادة ثثة المواطن في الحكومة: وذلك نتيجة لثفافيتها في طرح وتبرير سياساتها وخدماتها وعدالتها ومكافحتها للفساد ومسائلتها لغير الملتزمين ومحاولتها الاستجابة لاحتياجات

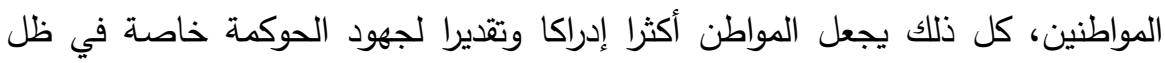
محدودية مواردها وأكثر استعدادا لمساندتها. r-رضا المواطنين والمستقيدين: وخاصة رضاهم عن السياسات والخدمات المقدمة لهم. فهناك علاقة مباشرة بين الحوكمة وزيادة ثقة المواطن في الحكومة من جانب ورضا وضان المواطنين وسعادتهم من جانب آخر • r- المتابعة والرقابة الفعالة للمواطنين، والمحليات، والجمعيات الأهلية: وذلك لأهميتها في الرقابة على جودة الخدمات وأوجه النفقات بفضل توفير الثفافية، ووجود قواعد للمساءلة ولة ولئ والمحاسبة يكن اللجوء إليها. ع - الوصول لقرارات أكثر حكمة وشاده: لأنها مبينة على الثفافية والمشاركة والمعلومات السليمة التي تعكس رؤى الأطراف المختلفة المعنية والتي يُعد بعضها- كالمجتمع المدني - أكثر قرباً من المواطنين ودراية بمشكلاتهم من الحكومة. ه- الحصول على الخدمات بسعر مناسب وجودة مناسبة: ويرجع ذلك نتيجة لغياب الرشوة والوساطة وتحرى الكفاءة والفعالية واحترام القواعد والقوانين المنظمة لجودة الخدمة.

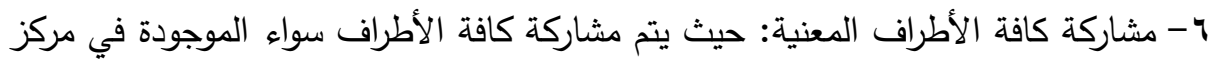
صناعة القرار أو في القاعدة والمجتمع في صناعة القرارات والسياسات بدءً من تعبيرهم عن احتياجاتهم، وإبداء أرائهم في السياسات والخدمات المساعدة في تتفيذها. 


$$
\begin{aligned}
& \text { مجلة العلوم البيئية } \\
& \text { معهد الدراسات والبحوث البيئية - جامعة عين شمس } \\
& \text { أحمد فوزي محمود وآخرون }
\end{aligned}
$$

V - القضاء عل جرائم عديدة: كالجريمة المنظمة وعمودها القوى الفساد، وخلق فرص عمل أكثر نتيجة مكافحة الفساد.

^- إرساء الأسس اللازمة للارتقاء بالسياسات والخدمات المقدمة: من خلال كفاءة وجودة واستجابة أكبر، واحترام لمبادئ القانون وقدرة على النفاذ والوصول للمواطنين والمناطق

$$
\text { الأكثر احتياجاً. }
$$

9- توفر سُبل وقنوات متعددة لمساءلة ومحاسبة المسئولين: وهو ما يجعل المساءلة أكثر سهولة وفعالية، وقد تكون سُبل وقنوات المساءلة داخلية أي من داخل الجهة التي يتم مساءلتها، كإدارة التفتيش أو المتابعة ، أو خارجية من خلأل مجلس وفوله أمناء أو جمعية أهلية

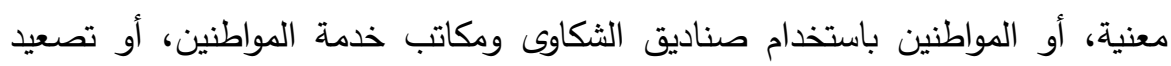

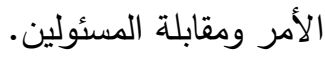

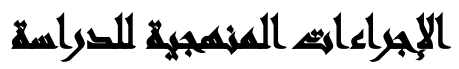

منهج الاراسة: استخدم الباحث المنهج الوصفي التحليلي وقد بُني هذا المنهج على الجمع بين الدراسة النظرية والدراسة الميدانية، حيث اعتمد الباحث على إجراء دراسة ميدانية لعينة

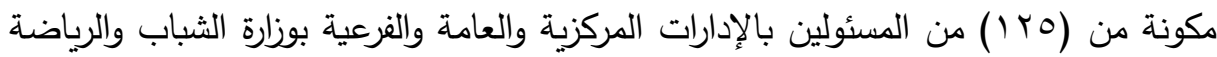
على مستوى جمهورية مصر العربية ، وتم اختبار فروض الدراسة من خلال الاستعانة بحزم البرامج الإحصائية (spss)، لإمكانية تصميم النتائج المتعلقة باختبارات الفروض على على مجتمع

$$
\text { • أدوات الدراسةة: تم إعداد استمارة استبيان وتكونت من: }
$$


• استمارة استبيان للمسئولين عينة الدراسة، وتمثلت في المحاور التالية (علاقة الحوكمة بتحسين بيئة العمل - علاقة الحوكمة بتحسين الأداء - علاقة الحوكمة بمبدأ المساءلة ومكافحة الفساد - معوقات تطبيق الحوكمة)، وقد بلغ عدد أسئلة الاستمارة(ب بـأسؤال.

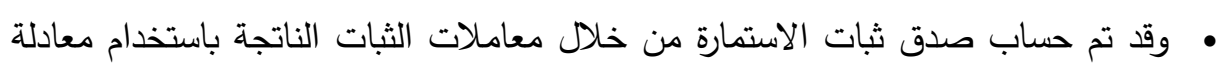

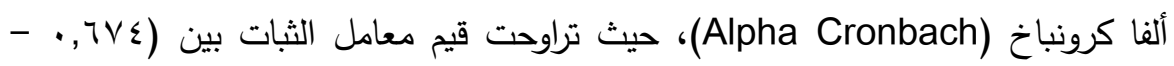

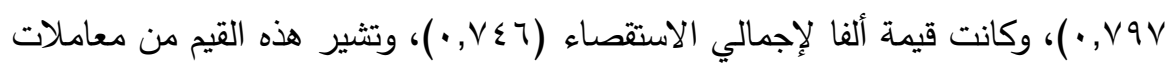

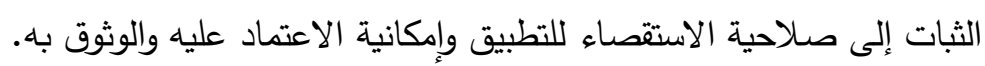

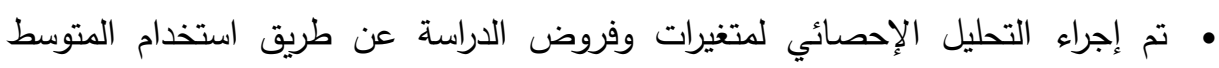

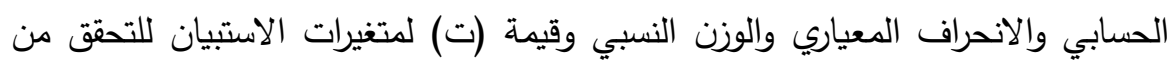
صحة فروض الدراسة.

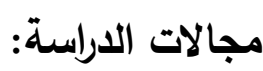
المجال البشرى: اشتملت عينة الدراسة على (Y0) مسئولا (وكيل وزارة - رئيس إدارة مركزية- مدير عام - مدير إدارة فرعية ) يمثلون الإدارات المركزية التابعة لوزارة الثباب والرياضة.

المجال المكاني: وزارة الثباب والرياضة بجمهورية مصر العربية. المجال الزمني: هي الفترة التي تستغرقها الدراسة بشقيها النظري والعملي. 
مجلة العلوم البيئية

معهد الدراسات والبحوث البيئية - جامعة عين شمس لئن

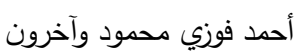

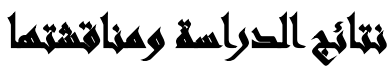

وصف نتائج البيانات الأولية لعينة الدراسة:

جدول ( ) : يوضح توزيع عينة الدراسة حسب متغير الوظيفة

\begin{tabular}{|c|c|c|}
\hline النسبة \% & ك5 & الوظيفة \\
\hline$\% \wedge$ & 1. & وكيل وزارة \\
\hline$\% \wedge$ & 1. & رئيس إدارة مركزية \\
\hline$\%$ \%, ₹ & $\varepsilon \wedge$ & مدير إدارة عامة \\
\hline$\% \leq 0,7$ & ov & مدير إدارة فرعية \\
\hline$\% 1 \ldots$ & ro & الإجمالي \\
\hline
\end{tabular}

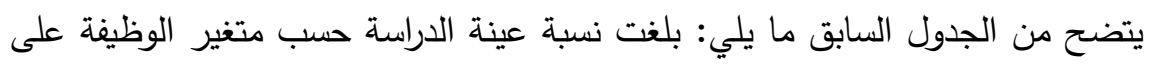

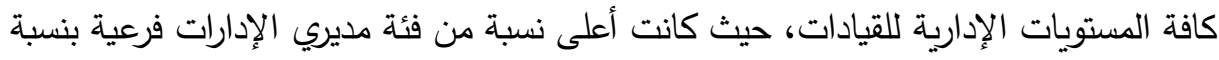

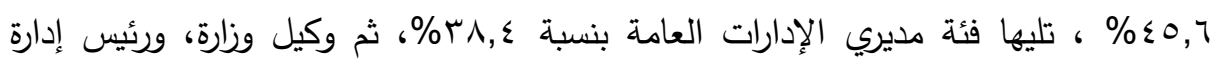

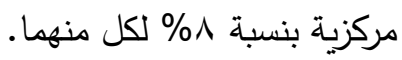


مجلة العلوم البيئية

معهد الدراسات والبحوث البيئية - جامعة عين شمس لبئه

أحمد فوزي محمود وآخرون

• التحليل الإحصائي لمتغيرات الدراسة:

جدول (Y): يوضح الإحصاء الوصفي لقياس أراء عينة الدراسة في مدى علاقة الحوكمة

بتحسين البيئة التتظيمية

\begin{tabular}{|c|c|c|c|c|c|c|c|c|c|c|}
\hline \multicolumn{2}{|c|}{ لا أوافق علي } & \multicolumn{2}{|c|}{ لا أوافق } & \multicolumn{2}{|c|}{ محايد } & \multicolumn{2}{|c|}{ أوافق } & \multicolumn{2}{|c|}{ أوافق جداً } & \multirow[t]{2}{*}{ العبارات } \\
\hline$\%$ & ك & $\%$ & ك5 & $\%$ & ك5 & $\%$ & ك & $\%$ & ك & \\
\hline \multirow[t]{3}{*}{$\wedge$} & 1. & $v \vee, 7$ & $9 V$ & & & $V, r$ & 9 & $V, r$ & 9 & تطبق الإدارة مفهوم ومبادئ الحوكمة بشكل \\
\hline & & & & $\wedge$ & 1. & $1 \cdot, \varepsilon$ & 14 & $\wedge 1,7$ & $1 \cdot r$ & 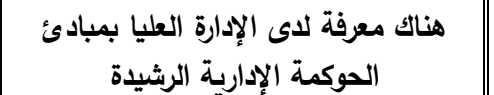 \\
\hline & & & & & & 9,7 & ir & $9 ., \leqslant$ & 114 & 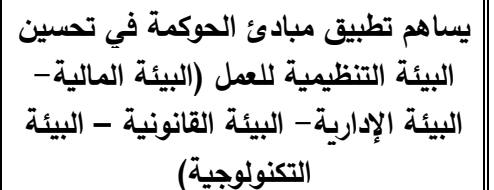 \\
\hline & & & & & & $r$. & ro & $\Lambda$. & $1 \ldots$ & |تحقق الحوكمة الايمقراطية في عملية اتخاذ \\
\hline & & & & & & 71,7 & v v & $\mu \wedge, \xi$ & $\leq \Lambda$ & 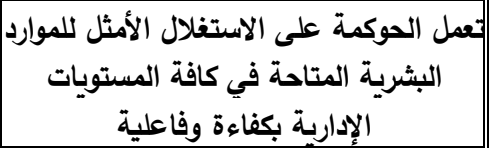 \\
\hline & & & & & & $0 \vee, T$ & VY & $\leqslant \varphi, \xi$ & or & تهال وتحديد الحوكمة إلى تأسيس نظام والمسئوليات وميثاق إدي \\
\hline
\end{tabular}

(المصدر : من بيانات التحليل الإحصائي)

يتضح من الجدول السابق ما يلي: تتجه معظم إجابات عينة الدراسة نحو الموافقة على الإسى

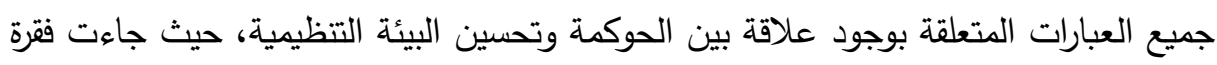
"يساهم تطبيق مبادئ الحوكمة في تحسين البيئة التظيمية للعمل (البيئة المالية- البيئة 


\section{مجلة العلوم البيئية \\ معهد الدراسات والبحوث البيئية - جامعة عين شمس \\ أحمد فوزي محمود وآخرون}

الإدارية- البيئة القانونية - البيئة التكنولوجية)"، بدرجة موافقة (أوافق جدا بنسبة ع,. 9\%\%)،

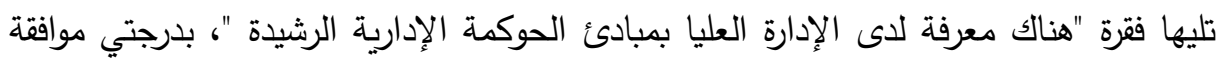

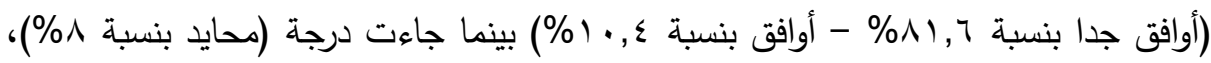

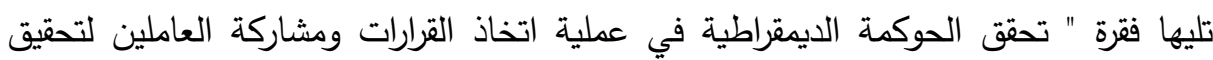

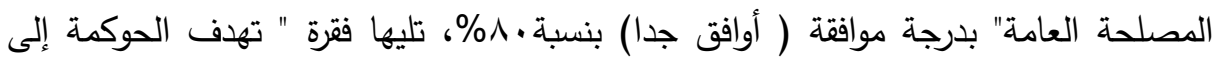
تأسيس نظام إداري فعال وتحديد المهام والمسئوليات وميثاق أخلاقيات الوظيفة"، بدرجتي لواتئه

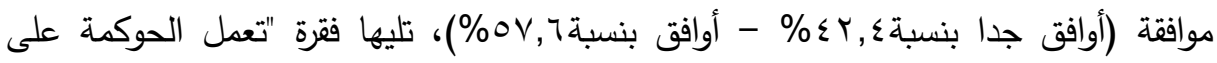
الاستغلال الأمثل للموارد البشرية المتاحة في كافة المستويات الإدارية بكفاءة وفاعلية"،

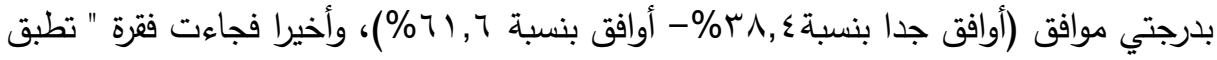

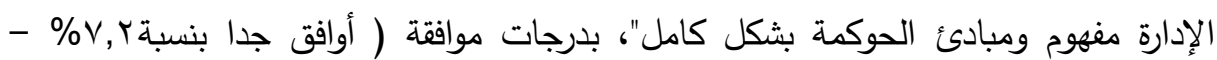

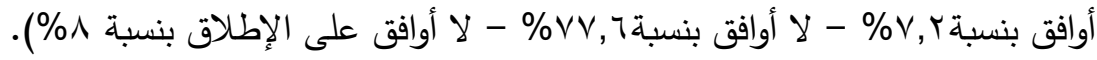
جدول (ץ): قياس أراء عينة الدراسة في مدى علاقة الحوكمة بتحسين البيئة المادية

\begin{tabular}{|c|c|c|c|c|c|c|c|c|c|c|}
\hline \multicolumn{2}{|c|}{ لا أوافق علي } & \multicolumn{2}{|c|}{ لا أوافق } & \multicolumn{2}{|c|}{ محايد } & \multicolumn{2}{|c|}{ أوافق } & \multicolumn{2}{|c|}{ أوافق جداً } & \multirow[t]{2}{*}{ العبارات } \\
\hline$\%$ & ك5 & $\%$ & ك5 & $\%$ & 5 & $\%$ & ك & $\%$ & ك & \\
\hline & & 9,7 & Ir & r $7, \varepsilon$ & $r r$ & $r \wedge, \varepsilon$ & $\leqslant \wedge$ & $r \bullet, \tau$ & rr & تساعد الحوكمة فى تحسين البيئة المادية \\
\hline & & & & Ir & 10 & $r \varepsilon, \varepsilon$ & $\varepsilon r$ & or, & $7 V$ & لتطبيق معايير الحوكمة ضرية لترورة توفير بيئة \\
\hline & & $\varepsilon, \wedge$ & 7 & & & $00, r$ & 79 & $\varepsilon$. & o. & 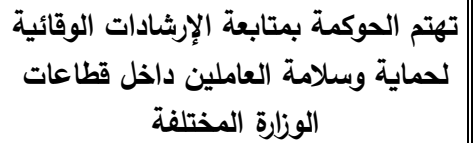 \\
\hline
\end{tabular}


مجلة العلوم البيئية

معهد الدراسات والبحوث البيئية - جامعة عين شمس لبئه

أحمد فوزي محمود وآخرون

\begin{tabular}{|c|c|c|c|c|c|c|c|c|c|c|}
\hline \multicolumn{2}{|c|}{ لا أوافق علي } & \multicolumn{2}{|c|}{ لا أوافق } & \multicolumn{2}{|c|}{ محايد } & \multicolumn{2}{|c|}{ أوافق } & \multicolumn{2}{|c|}{ أوافق جداً } & \multirow[t]{2}{*}{ العبارات } \\
\hline$\%$ & ك5 & $\%$ & ك5 & $\%$ & ك5 & $\%$ & كs & $\%$ & ك & \\
\hline & & $\wedge, \wedge$ & 11 & $1 \wedge, \varepsilon$ & rr & $7 \varepsilon$ & $\Lambda$. & $\wedge, \wedge$ & 11 & 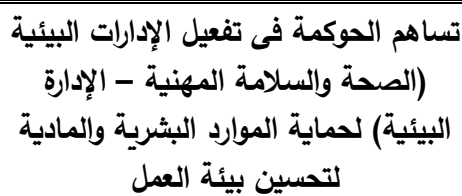 \\
\hline & & $1 \wedge, \varepsilon$ & $r r$ & $r, r$ & $\varepsilon$ & $\leqslant V, r$ & 09 & $r 1, r$ & rq & تؤدى تطبيق مبادئ الحوكمة إلى تحقيق التنمية المستدة داخل المنظمة \\
\hline
\end{tabular}

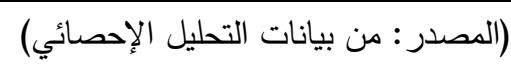

يتضح من الجدول السابق ما يلي: تتجه معظم إجابات عينة الدراسة نحو الموافقة على الإسى

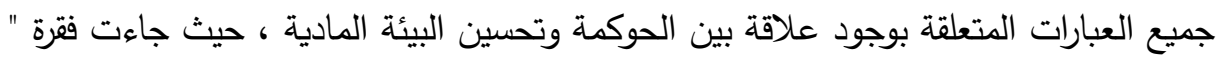
لتطبيق معايير الحوكمة ضرورة توفير بيئة نظيفة وصحية للعاملين تساعد في ممارسة أعمالهم

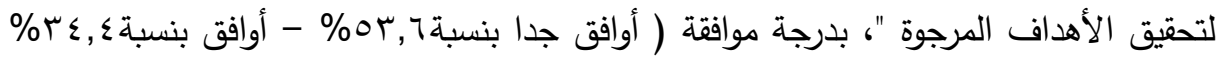

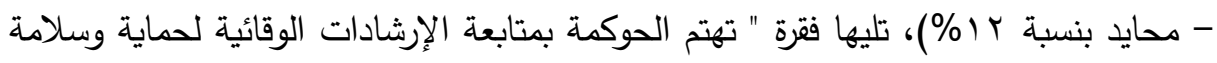

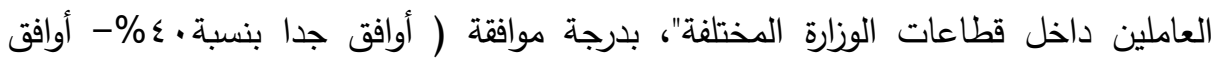

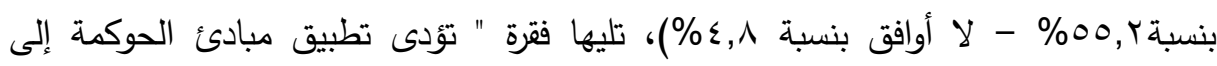

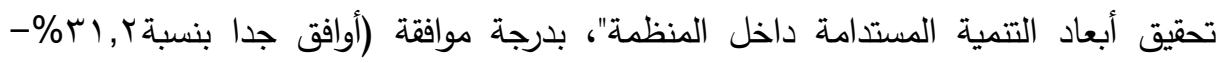

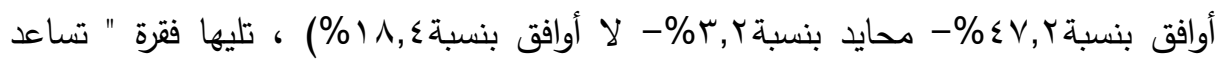

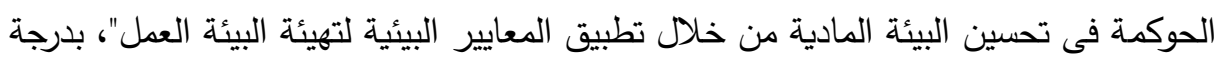

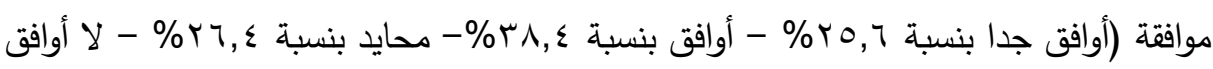

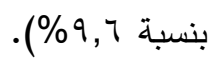

يُشير ذلك إلى أن هناك موافقة بشكل كبير من أفراد عينة الدراسة على أن وجود علاقة

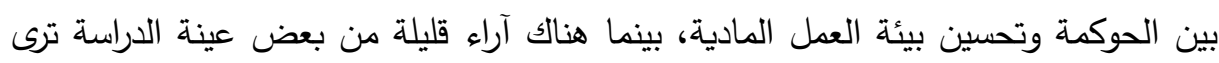

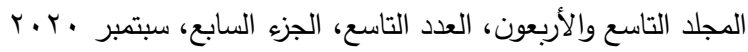

$$
\begin{aligned}
& \text { الترقيم الدولي 0826-0 الإنون، }
\end{aligned}
$$


أن تطبيق مبادئ الحوكمة لا يؤدى إلى تحسين البيئة المادية أو تحقيق أبعاد التتمية

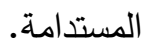

اختبار صحة فروض الاراسة: تم اختبار صحة الفروض التي تم طرحها، وذلك عن طريق استخدام اختبار (T) ومعامل الارتباط البسيط بين المتغير التابع والمتغيرات المستقلة،

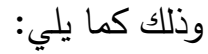

• اختبار صحة الفرض الرئيس الأول: "توجد علاقة جوهرية بين الحوكمة وتحسين البيئة الداخلية للعمل". ولاختبار هذا الفرض، تم إجراء اختبار المتوسط الحسابي والانحراف المعياري والوزن النسبي وقيمة (ت) بين تطبيق مفهوم الحوكمة وتحسين البيئة الداخلية للعمل للتحقق من صحة أو عدم صحة الفرض، وجاءت والنتائج كما يلي:

جدول (؛): يوضح نتائج التحليل الإحصائي لعبارات علاقة وتحسين البيئة الداخلية للعمل

\begin{tabular}{|c|c|c|c|c|c|c|}
\hline المعنوية & $ت$ & الترتي & المون النسبي & المعياري & الحسابي & العبارات \\
\hline,$\ldots 1$ & YY,YY & 1 & $\{0,4$ & $\cdot, q \vee Y \backslash q$ & $r, Y \wedge$ & تطبق الإدارة مفهوم ومبادئ \\
\hline,$\ldots 1$ & $\wedge \wedge, \uparrow$ & $r$ & $q \leq, V Y$ & זי & \&,VM & هباك معرفة لادى الإدارة العليا \\
\hline,$\ldots$, & $|\wedge \theta, r v|$ & 1 & $9 \wedge, \cdot \wedge$ & $\cdot, r q \diamond \vee \wedge$ & $\varepsilon, 9 . \leqslant$ & 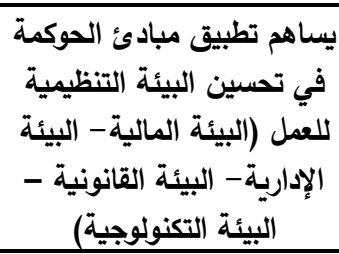 \\
\hline$\cdot, \ldots$ & דצוT, & $r$ & 94 & $\cdot, 4.171$ & $\varepsilon, \wedge$ & 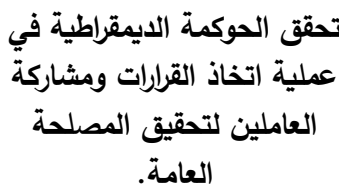 \\
\hline
\end{tabular}

402

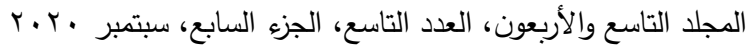

$$
\begin{aligned}
& \text { الترقيم الدولي 0826- ISSN 1110 }
\end{aligned}
$$




$$
\begin{aligned}
& \text { مجلة العلوم البيئية } \\
& \text { معهد الدراسات والبحوث البيئية - جامعة عين شمس لئن } \\
& \text { أحمد فوزي محمود وآخرون }
\end{aligned}
$$

\begin{tabular}{|c|c|c|c|c|c|c|}
\hline المعنوية & ت & الترتي & الوزن النسئوي & الانحراف & الحستوسطي & العبارات \\
\hline$\cdot, \cdots$, & $1 \ldots, r v o$ & 0 & $\wedge \vee, \uparrow \wedge$ & •, \&AAYY & $\varepsilon, \Gamma \wedge \varepsilon$ & 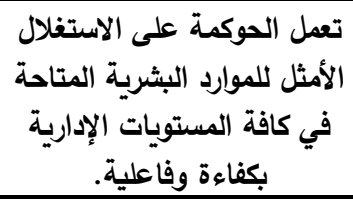 \\
\hline$\cdot, \ldots$ & $99, \uparrow \wedge 0$ & $\varepsilon$ & $\wedge \wedge, \& \wedge$ & ه & \&, \& & 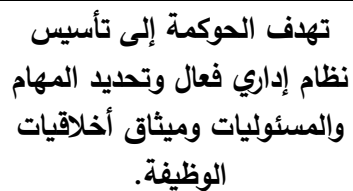 \\
\hline,,$\ldots 1$ & $11 \varepsilon, Y \circ V$ & - & $\Lambda_{0,1}$ & Vז & $\varepsilon, r \circ 0$ & إجمالي البعد \\
\hline
\end{tabular}

(المصدر : من بيانات التحليل الإحصائي) يتضح من الجدول السابق ما يلي: - أظهرت نتائج وصف عبارات بُعد (علاقة الحوكمة بتحسين البيئة التظظيمية)، أن المتوسط

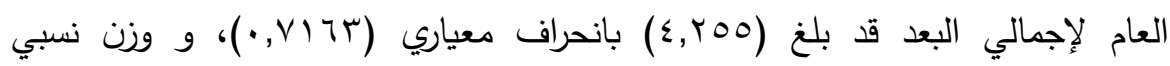

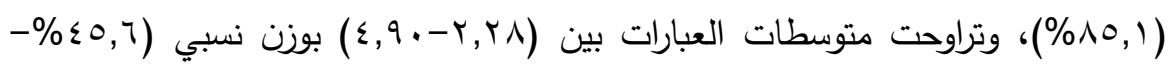
.$(\% 9 \wedge, \wedge$

- - تُشير تلك النسب إلى موافقة عينة الدراسة على أن هناك علاقة بين الحوكمة وتحسين البيئة التنظيمية للعمل. - أثثتت النتائج من خلال قيم (ت) أن جميع القيم دالة إحصائياً عند مستوى معنوية

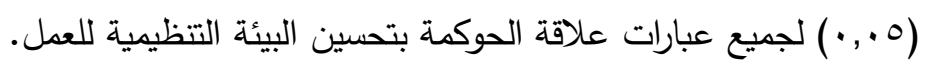
من العرض السابق يتضح أنه "توجد علاقة ذات دلالة إحصائيا بين تطبيق مفهوم الحوكمة وتحسين البيئة الداخلية للعمل (البيئة المالية - البيئة الإدارية - البيئة القانونية البيئة التتظيمية)". ومن ثم تم قبول الفرض الرئيس الأول، وكذلك الفروض الفرعية المنبثقة منه.

$$
\begin{aligned}
& \text { r. . . المجلد التاسع والأربعون، العدد التاسع، الجزء السابع، سبتمبر }
\end{aligned}
$$

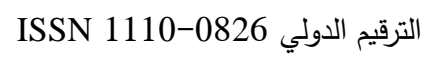


مجلة العلوم البيئية

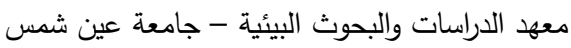

أحمد فوزي محمود وآخرون

• اختبار صحة الفرض الفرعي الثاني: "توجد علاقة جوهرية بين الحوكمة وتحسين الأداء".

ولاختبار هذا الفرض، تم إجراء اختبار المتوسط الحسابي والانحراف المعياري والوزن النسبي وقيمة (ت) بين تطبيق مفهوم الحوكمة، وتحسين الأداء للتحقق من صحة أو عدم التحري

صحة الفرض، وجاءت النتائج كما يلي:

جدول (0): نتائج التحليل الإحصائي لعبارات علاقة الحوكمة بتحسين أداء العاملين

\begin{tabular}{|c|c|c|c|c|c|c|}
\hline المعنوية & ت & الترتيب & المزني المئوي & الالمعياري & الحستوسط & العبارات \\
\hline$\cdot, \cdots 1$ & $74,7 \leq 7$ & $r$ & $q \cdot, \wedge \wedge$ & $\cdot, \vee Q \wedge r r$ & $\varepsilon, 0 \leq \varepsilon$ & 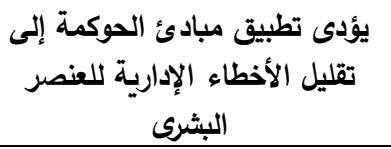 \\
\hline$\cdot, \ldots 1$ & צ & 1 & $q \leq, Y \leq$ & $\cdot, \vee \vee . \Delta q$ & $\varepsilon, V \backslash Y$ & تساهم الحوكمة في زيادة وتطور أداء العنصر البثرى \\
\hline$\cdot, \cdots 1$ & $r \leq, 799$ & 0 & $\neg 7, \wedge \wedge$ & $1, \cdot \vee \wedge \leq 1$ & $r, r \leq \varepsilon$ & تحديث الأنظمة وتمارسات الحوكمة العمل على إخراء ات \\
\hline$\cdot, \cdots 1$ & 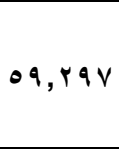 & $r$ & $\vee 9,7 \wedge$ & $\cdot, V \otimes 11 V$ & $r, 9 \wedge \varepsilon$ & 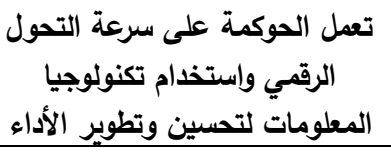 \\
\hline$\cdot, \cdots 1$ & $r q, \ldots 1$ & $\varepsilon$ & 79,94 & $1, r \leq \vee \vee \wedge$ & $r, \& 97$ & تهتم الحوكمة بتدريب وتطوير أداء العنشري وتحفيزه للتحسين \\
\hline$\cdot, \ldots 1$ & $O Y, \& \Delta V$ & - & $\Lambda \cdot, r r$ & $\cdot, \wedge 0090$ & $2, .17$ & إجمالي البعد \\
\hline
\end{tabular}

المصدر : من بيانات التحليل الإحصائي 
يتضح من الجدول السابق ما يلي:

- أظهرت نتائج وصف عبارات بُعد (علاقة الحوكمة بتحسين أداء العاملين)، أن المتوسط

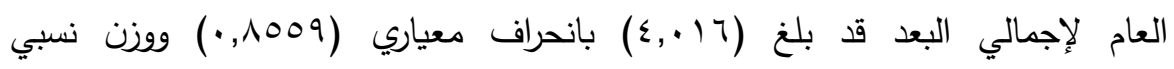

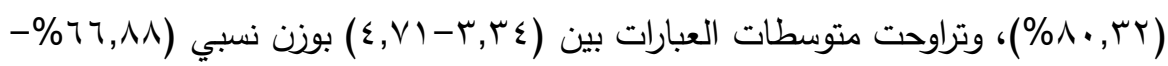

.$(\% 9 \varepsilon, r \varepsilon$

- تُشير تلك النسب إلى موافقة عينة الدراسة على أن الحوكمة لها علاقة كبيرة بتحسين أداء

العاملين.

- أثثتت النتائج من خلال قيم (ت) كانت جميع القيم دالة إحصائياً عند مستوى معنوية (0. (· •) لجميع عبارات علاقة الحوكمة بتحسين أداء العاملين.

من العرض السابق يتضح أنه توجد علاقة ذات دلالة إحصائيا بين تطبيق مفهوم

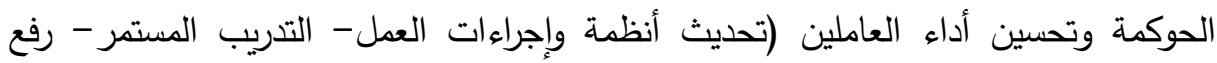
وتطوير كفاءة العنصر البشرى)، ومن ثم تم قبول الفرض الرئيس الثاني، وكذلك الفروض الفرعية المنبثقة منه.

• اختبار صحة الفرض الرئيس الثالث: "توجد علاقة جوهرية بين الحوكمة ومبدأ المساءلة ومكافحة الفساد". ولاختبار هذا الفرض، تم إجراء اختبار المتوسط الحسابي والانحراف المعياري والوزن النسبي وقيمة (ت) بين تطبيق مفهوم الحوكمة ومبدأ المساءلة ومكافحة

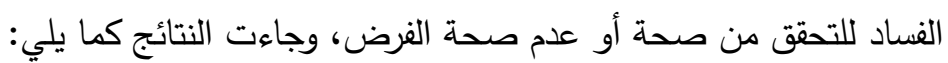


مجلة العلوم البيئية

معهد الدراسات والبحوث البيئية - جامعة عين شمس البية

أحمد فوزي محمود وآخرون

جدول (†): نتائج التحليل الإحصائي لعبارات علاقة الحوكمة ومبدأ المساءلة والمحاسبة ومكافحة الفساد

\begin{tabular}{|c|c|c|c|c|c|c|}
\hline المعنوية & $ت$ & الترتيب & المزن النسبي & المعياري & الحسابي & العبارات \\
\hline$\cdot, \ldots$ & $V \vee, T V V$ & r & $\wedge q, 1 r$ & . & $\{, \leqslant 07$ & 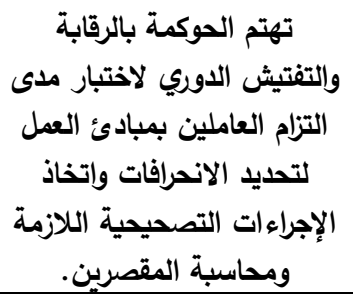 \\
\hline$\cdot, \ldots$ & $\varepsilon Y, Y$ & $r$ & $\wedge \vee, \uparrow \wedge$ & $1, .9 .94$ & $\varepsilon, \Gamma \wedge \varepsilon$ & 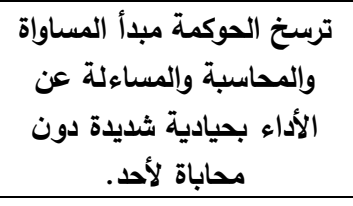 \\
\hline$\cdot, \ldots$ & $\Lambda \leqslant, 01 T$ & 1 & 99 & סזוד, & $£, \wedge$ & 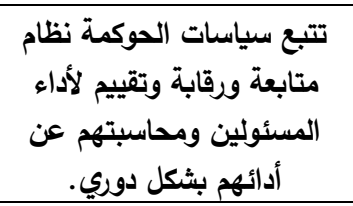 \\
\hline$\cdot, \cdots$, & $r q, 7 q$ & \{ & $\vee \wedge, \xi$ & $1,1 . \leq x \leq$ & $r, q r$ & اللتزم مبادئ الحوكمة بمحاسبة الالتزام بالقوانين في حالة عدم \\
\hline$\cdot, \ldots 1$ & $r r, \cdot v q$ & ○ & VY,qY & 1, rruqq & $r, T \leqslant \Lambda$ & 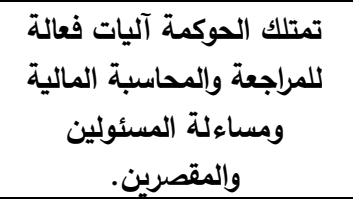 \\
\hline$\cdot, \ldots$ & r & - & $\Lambda \varepsilon, \Lambda r r$ & -, 10409 & $\varepsilon, Y \leqslant 17$ & إجمالي البعد \\
\hline
\end{tabular}

406

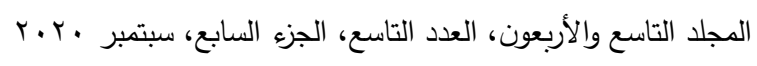

الترقيم الدولي 0826- ISSN 1110 
يتضح من الجدول السابق ما يلي:

- أظهرت نتائج وصف عبارات بُعد (علاقة الحوكمة بمبدأ المساءلة والمحاسبة)، أن

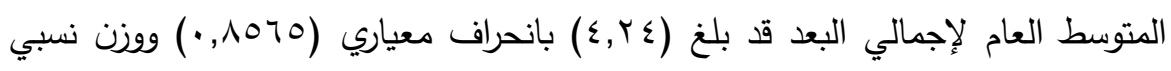

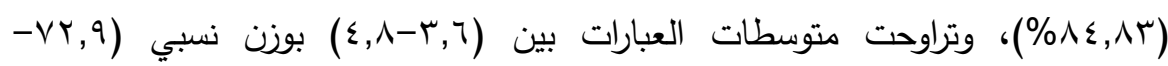
. $(\% 97, \cdot$

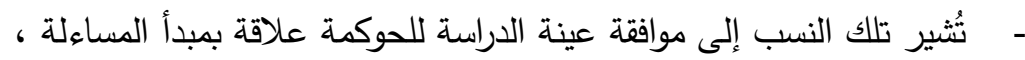
- أثبتت النتائج خلال قيم (ت) كانت جميع القيم دالة إحصائياً عند مستوى معنوية (0. . .) لجميع عبارات علاقة الحوكمة ومبدأ المساءلة. من العرض السابق يتضح أنه " توجد إله علاقة ذات دلالة إحصائيا بين تطبيق مفهوم الحوكمة ومبدأ المساءلة والمحاسبة ومكافحة

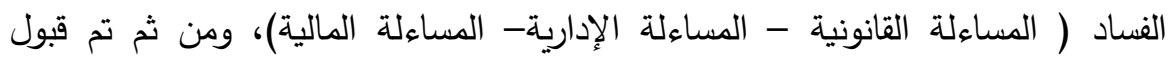
الفرض الرئيس الثالث، وكذلك الفروض الفرعية المنبثقة منه. توصلت الدراسة إلى عدة نتائج منها الآتي: 1- هناك علاقة دالة إحصائيا بين الحوكمة وتحسين البيئة التظيمية للعمل ( البيئة المالية-

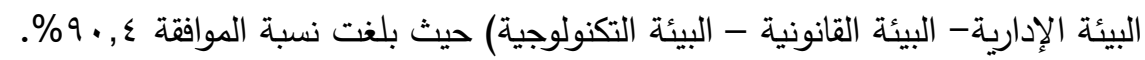
r-هناك علاقة دالة إحصائيا بين الحوكمة وتحسين البيئة المادية ( تطبيق المعايير البيئيةتوفير بيئة نظيفة وصحية للعاملين- تفعيل الإدارات البيئية- تحقيق أبعاد التتمية

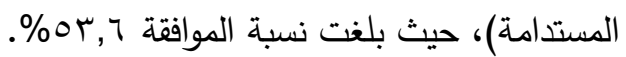

r-هنالك علاقة دالة إحصائيا بين الحوكمة وتحسين أداء العاملين، حيث بلغت بلغ نسبة الموافقة $\% \wedge \varepsilon$

ع- هناك علاقة دالة إحصائيا بين الحوكمة والإفصاح والثفافية، حيث بلغت نسبة الموافقة $\% \wedge r, \varepsilon$ 


$$
\begin{aligned}
& \text { مجلة العلوم البيئية } \\
& \text { معهد الدراسات والبحوث البيئية - جامعة عين شمس لكس } \\
& \text { أحمد فوزي محمود وآخرون }
\end{aligned}
$$

0- هناك علاقة دالة إحصائيا بين الحوكمة ومبدأ المساءلة والمحاسبة حيث بلغت نسبة

$$
\text { الموافقة \%ᄉᄉ }
$$

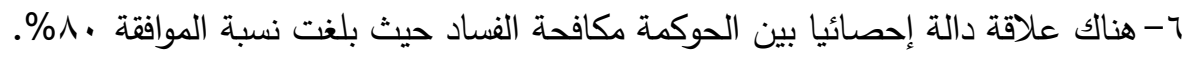
V- هناك معوقات تُحد من تطبيق مبادئ الحوكمة داخل الوزارة حيث بلغت نسبة الموافقة \% Tr, \&

\section{اللزوصياتص}

بناء على ما توصلت إليه الدراسة الحالية من نتائج قام " الباحثون" بعمل خطة لتوصيات الدراسة وهى مرتبة بحسب أهميتها لما تم الوصول إليه من نتائج وفقاً للدراسة الميدانية، وهى لثى لئه كالتالي: - n

408

$$
\begin{aligned}
& \text { r. . . المجلد التاسع والأربعون، العدد التاسع، الجزء السابع، سبتمبر } \\
& \text { الترقيم الدولي 0826- ISSN 1110 }
\end{aligned}
$$




$$
\begin{aligned}
& \text { مجلة العلوم البيئية } \\
& \text { معهد الدراسات والبحوث البيئية - جامعة عين شمس لكس } \\
& \text { أحمد فوزي محمود وآخرون جانية }
\end{aligned}
$$

\begin{tabular}{|c|c|c|c|c|}
\hline المدى الزمني & جهة التفيذ & متطلبات التطبيق & التوصية & p \\
\hline بصفة مستمرة & المستويات الإداداتيّة & 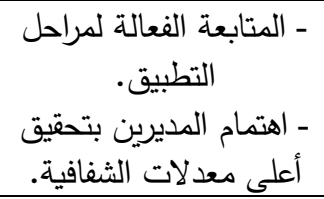 & 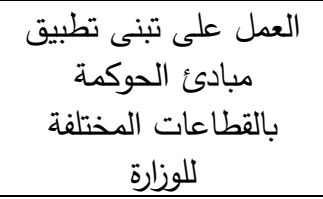 & 1 \\
\hline بصفة مستمرة & 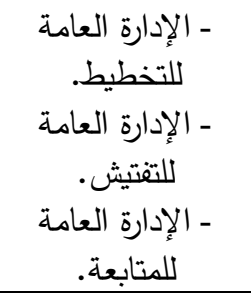 & 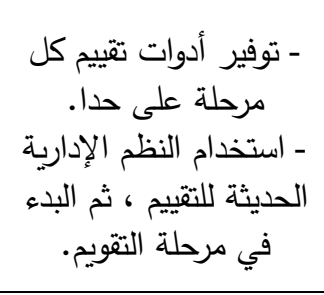 & 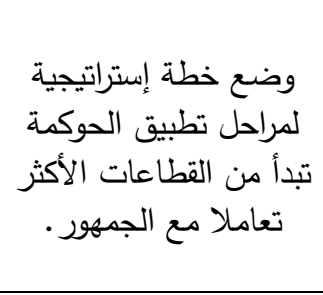 & r \\
\hline بصفة مستمرة & 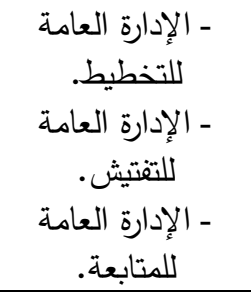 & 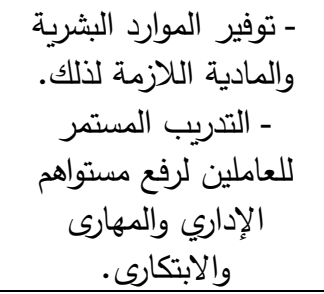 & 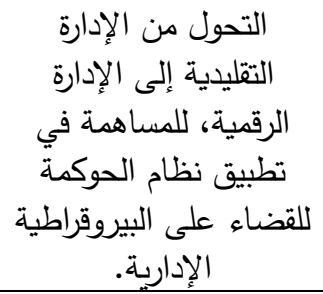 & $r$ \\
\hline بصفة مستمرة & في الإدارية المختويات القيادات & - البشع رؤيدة للتخطية وإستراتيجية & 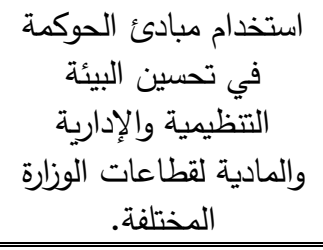 & $\varepsilon$ \\
\hline
\end{tabular}

$$
\begin{gathered}
\text { المجلد التاسع والأربعون، العدد التاسع، الجزء السابع، سبتمبر · r. الترقيم الدولي 0826- } \\
\text { ISSN 1110 }
\end{gathered}
$$




$$
\begin{aligned}
& \text { مجلة العلوم البيئية } \\
& \text { معهد الدراسات والبحوث البيئية - جامعة عين شمس له } \\
& \text { أحمد فوزي محمود وآخرون }
\end{aligned}
$$

\section{zall}

أحمد محمد، هاجر على (Y V r r): أثر البيئة التظظيمية على الأداء الوظيفي للعاملين، بحث مقدم لقسم الأعمال، جامعة الثرق الأوسط.

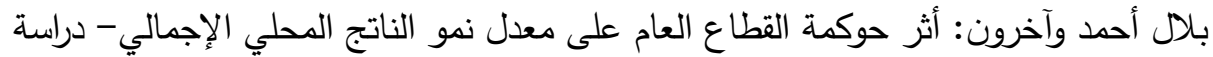

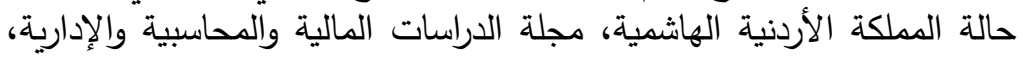

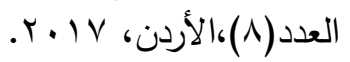

ديوان الفتوى والتشريع: الحوكمة والأداء المؤسسي في القطاع العام، دولة فلسطين، 7 ـ ـ ـ ـ

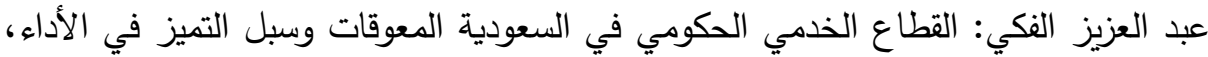

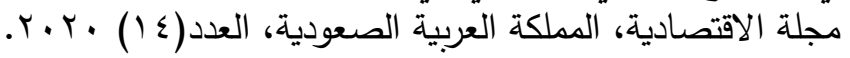

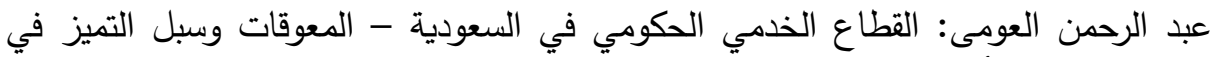

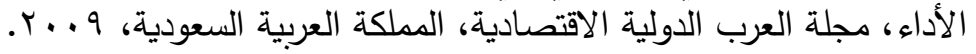

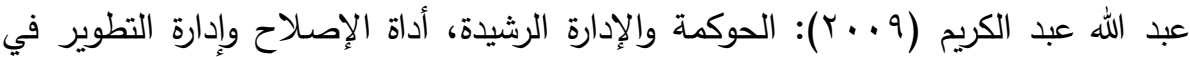
المنطقة العربية، بيروت ، لبنان.

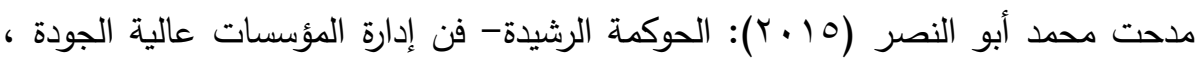
المجموعة العربية للتدريب والنشر ، القاهرة، الطبعة الأولى. الني.

محمد البشير، عبد الغنى ددان: حوكمة المؤسسات ودورها في تحسين أداء المؤسسة، مجلة القادية

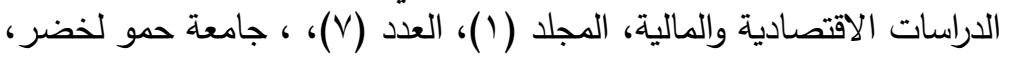

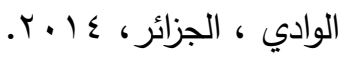

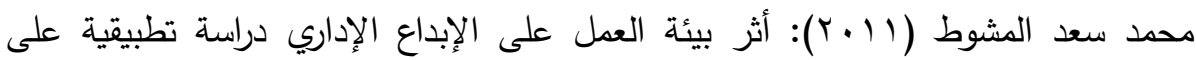

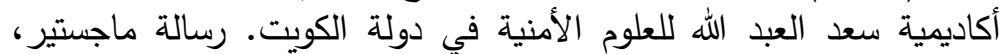

$$
\text { جامعة الثرق الأوسط، الكويت. }
$$

مركز المعلومات ودعم اتخاذ القرار: دليل تقييم الحوكمة الرشيدة في القطاعات الخدمية،

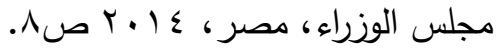

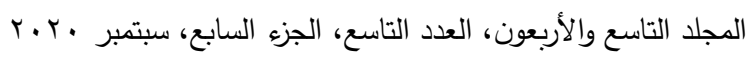

$$
\begin{aligned}
& \text { الترقيم الدولي 0826-0 الإنون، }
\end{aligned}
$$




$$
\begin{aligned}
& \text { مجلة العلوم البيئية } \\
& \text { معهد الدراسات والبحوث البيئية - جامعة عين شمس له } \\
& \text { أحمد فوزي محمود وآخرون }
\end{aligned}
$$

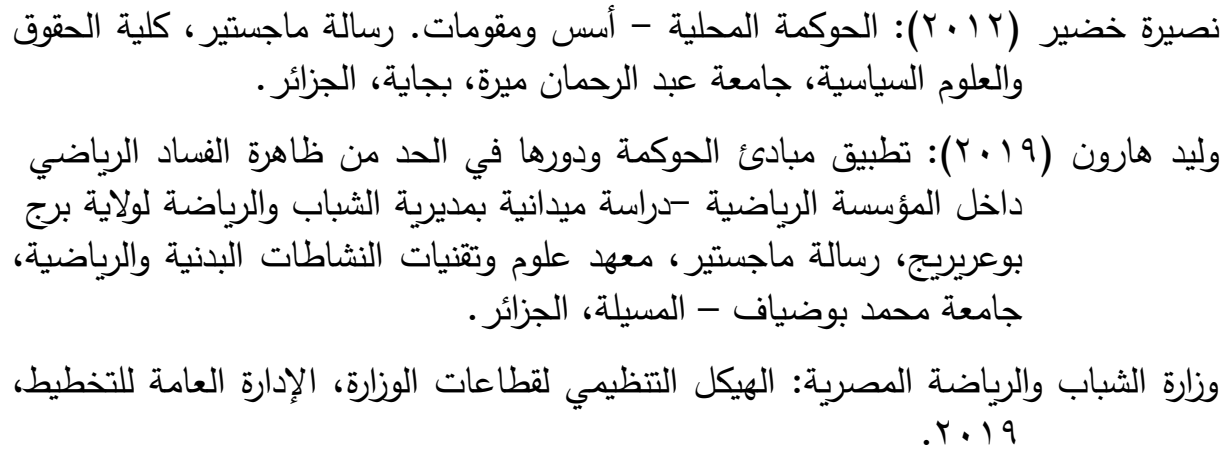

Freeland, C. (2007): Basel Committee Guidance on Corporate Governance for Banks, paper presented to: Coorporate Governance and Reform: Paving the Way to Financial Stability and Development, a conference organized by the Egyptian Banking Institute, Cairo, May $7-8$.

Glenda B. Arrington: Can Four Generations Create Harmony Within a Public-Sector Environment, International Journal of Applied Management and Technology ,(2018), Volume 17, Issue 1, Pages 1-21 CWalden University, LLC, Minneapolis, MN DOI:10.5590/IJAMT.2018.p.17.1.01.

Organization for economy cooperation and developement (2000): principales of corporate governance, (2019), OECD publications survi.

Sugeng wohyu, et al, (2019): The effect of transformational style on leadership work environment style on organizational commitments to improve work satisfaction of employees, journal of management, Volume 5, No.5.

Tanweer Hasan, et al.: Role of governance on oerformance of microfinance institutions in bengladesh, journal Eurasian economic review Vol 9 (1)91-109

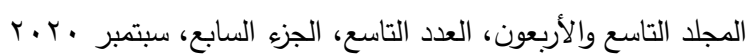

$$
\begin{aligned}
& \text { الترقيم الدولي 0826- ISSN 1110 }
\end{aligned}
$$




$$
\begin{aligned}
& \text { مجلة العلوم البيئية } \\
& \text { معهد الدراسات والبحوث البيئية - جامعة عين شمس } \\
& \text { أحمد فوزي محمود وآخرون }
\end{aligned}
$$

UNDP: (1997): Reconceptualising Governance, Discussion Paper (2), P10. Williamson, Q. E, (2009): The Mechanism of Governance, Oxford University Press, p .18.

\title{
THE ROLE OF E GOVERNANCE IN IMPROVING THE WORK ENVIRONMENT WITHIN GOVERNMENT SERVICE SECTORS - APPLIED STUDY ON THE MINISTRY OF YOUTH AND SPORTS
}

\author{
Ahmed F. Mahmud ${ }^{(1)}$; Mahmud M. Abdel Hadi(2) \\ Shawky E. El-Ghitany ${ }^{(2)}$ and Abdel Nabi A. Khater ${ }^{(3)}$ \\ 1) Post graduate student at Institute of Environmental Studies and \\ Research, Ain Shams University 2) Faculty of Commerce, Ain Shams \\ University 3) Community Organization Institute Of Social In Cairo
}

\begin{abstract}
The study aims to identify "the role of governance in improving the work environment within the service government sectors by applying to the Egyptian Ministry of Youth and Sports, as well as studying the extent of benefiting from the application of governance in improving the regulatory environment and the physical environment within the Ministry of Youth and Sports as one of the most important service sectors that provide services to more categories In Egypt, they are the youth category, the nucleus of society, where the ministry is able to apply the principles of governance to eliminate administrative, organizational and environmental obstacles and achieve the goals that it

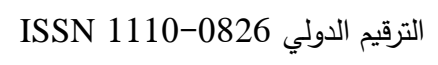

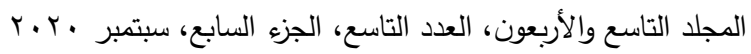




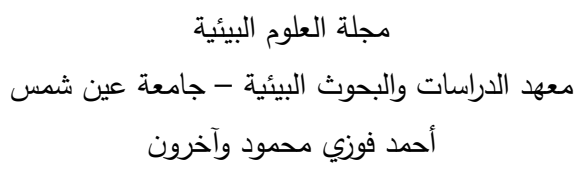

aspires to. The study was conducted on (125) individual officials in the higher management of the various sectors of the ministry, and the central, public and subordinate departments of the ministry on Republic level. The researchers used the inductive and deductive approach, and the descriptive and analytical approach to complete the study. A questionnaire was designed for the study sample officials to measure the impact and role of governance in improving the organizational and material environment and reducing corruption.

The researchers reached the following results: There is a statistically significant relationship between governance and improving the physical work environment.

Key words: governance, service government sectors, work environment.

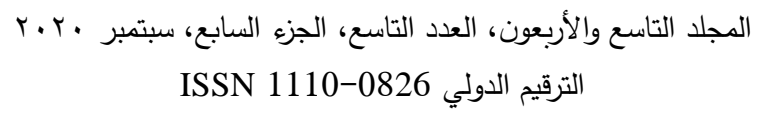

